\title{
Preferential Price and Trade Tied Aid in Fiji: Implications on Price Stability, Certainty and Output Supply
}

\author{
Mahendra Reddy
}

\begin{abstract}
The development of small developing states has long been influenced by foreign aid. Apart from the macro benefits of bridging the savings and investment gap and building the foreign exchange gap, it is also said to stabilise output price, provide price certainty and affect output price positively. In this paper I examine these three aspects in detail with respect to the price subsidy that Fiji's sugar industry has been receiving over the last three decades. Price stability is measured by examining the conditional variance by estimating a GARCH $(1,1)$ model and price certainty aspect is examined by testing if the forecast price is an unbiased and efficient predictor of the actual price. The price effect on supply response is examined by estimating the long and short run response equations. The price certainty analysis reveals that the forecast price is an unbiased and efficient predictor of actual price. The price stability test reveals that the world free market price is not volatile and therefore price stability is not a reason for preferential prices. Lastly, the supply response analysis reveals that in the long run, the price effect on output supply is transmitted via acreage change under sugarcane crop. In the short run, price has lagged effect on both sugarcane supply and acreage response. The inelastic price elasticities of output supply have important policy ramifications.
\end{abstract}

Key words: Price Volatility, Price Subsidy, Supply Response, Error Correction Model

\section{Introduction}

The developments of small developing states have long been influenced by aid money from developed countries. Economic literature notes one of the key role of aid as bridging the savings and investment gap which is a common problem in developing economies. Furthermore, aid will also bring in the necessary foreign exchange required for countries to trade.

Aid has been channelled to developing economies in several forms. Cash aid has been the most common and widely used and accepted. Its implications have been many and varied, some positive and some negative. Capital equipments and technical expertise has also played a significant role in aid deployment to developing economies which suffer from lack of human capital and a dearth of capital equipment.

Dean College of Business, Hospitality and Tourism Studies, Fiji National University, Suva, Fiji. E-mail:

Reddy_m@fit.ac.fjor mahendra.reddy@fnu.ac.fj 
The other form of aid, also widely used is what could be termed as "trade-tiedaid". Trade-tied-aid could be in the form of preferential prices. The novel purpose of trade-tied-aid is to encourage production thus ensuring that aid money is not wasted on consumption activities but rather, raise the productive capacity of the economy.

Pacific island countries (PICs) have been receiving the highest percapita aid for long. Amongst the PICs, PNG, Fiji, Solomons and Samoa are the countries which have received the highest amount of per capita aid.

However, despite receiving such high amount of aid money, the economic performance of most of the PICs has been below average of that of other small developing countries in the world. In most of the PICs, average per capita incomes have shown little change since independence-in some cases over 30 years ago. In most of these countries, population growth rates are still high as they have not yet entered the post-demographic transition stage, and total fertility rates are around 4 in some cases (e.g., Papua New Guinea, Marshall Islands, Solomon Islands, and Vanuatu). Hence, with population growth rates of 2.5 per cent or higher, the economies have had to average GDP growth of around 2.5 per cent just to maintain average per capita incomes. The economic performance of the PICs in the second half of the 1990s and the first half of the 2000s varied considerably from country to country. Cook Islands, Fiji, Kiribati, Samoa, Tonga, and Tuvalu all had positive per capita GDP growth during this period, while Republic of the Marshall Islands (RMI), the Federated States of Micronesia (FSM), Solomon Islands, and Vanuatu experienced negative per capita GDP growth, on average (Reddy and Duncan, 2005).

While Fiji amongst the PICs has done well, its performance has still been well below the potential for a developing country. Fiji is small island economy with total land area of 18,333 sq km. It Gross Domestic Product (GDP) consists mainly of Tourism receipts, sugar, fish, timber as well as garment export earnings. With a total population around 840,000, GDP growth rate has been marginally low over the last three decades thus keeping per capital income around US\$2,500.

Fiji's economic growth and development, up till late 1990's, can be tied to the growth and development of the sugar industry. However, while there seems to be some degree of consensus amongst the general public that the growth of the sugar industry is by and large due to the preferential prices that Fiji has been receiving since independence, there is lack of thorough research to establish the nature and magnitude of this effect. This lack of micro level studies is not only common in the Pacific, but also evident in agrarian economies such as the African region (Abrar, et. al, 2004). The argument put forward by policy makers in Fiji is that preferential prices have stabilised price volatility of the world market sugar prices thus providing stable income, have raised farm income both directly via higher price and indirectly via increased sugarcane supply via positive response to output supply. This paper examines in detail if preferential prices have indeed made these contributions. Furthermore, the agreements of preferential prices provide some degree of certainty on future prices. This certainty can be tested by examining if the forecast price, made 
at the beginning of a season by the industry, is an efficient and unbiased predictor of the actual price.

\section{Sugar Industry: a Brief Overview}

Sugar in Fiji existed well before it was grown commercially. The entry into commercial production was only undertaken by the European settlers in late 1800 . The first commercial enterprise in sugar got off the ground in 1862 when a European settler, David Whippy, erected a rudimentary mill on the island of Wakaya, with the hope of selling the sugar produced to merchants in Sydney (FSC, 1987). Since then sugarcane production continued to expand and it gained momentum with the establishment of the Colonial government which was instrumental in inviting foreign capital, technology and labour. The colonial government also persuaded the natives to release communal land for large scale sugarcane production. During the second half of the twentieth century, Fiji's inclusion in the Commonwealth Sugar Agreement (CSA) boosted the country's revenue from the trade of sugar. The CSA was a preferential agreement between the United Kingdom and the Commonwealth sugar-producing countries by which the UK guaranteed to purchase specified quantities of sugar for a negotiated price. Apart from the increase in the growers' share of proceeds and export earnings for the country, cane supply was boosted with the successful negotiation of the Sugar Protocol of the Lomé Convention in 1975 (and the SPS) in which Fiji secured market access and guaranteed prices. The prices, as Figure 1 shows, are two to three times higher than the world free market price. At the time that the UK entered the EU, the Sugar Protocol replaced the Commonwealth Sugar Agreement (CSA) of 1950.

Figure 1: Sugar Price Path under Alternative Markets, 1970-2002

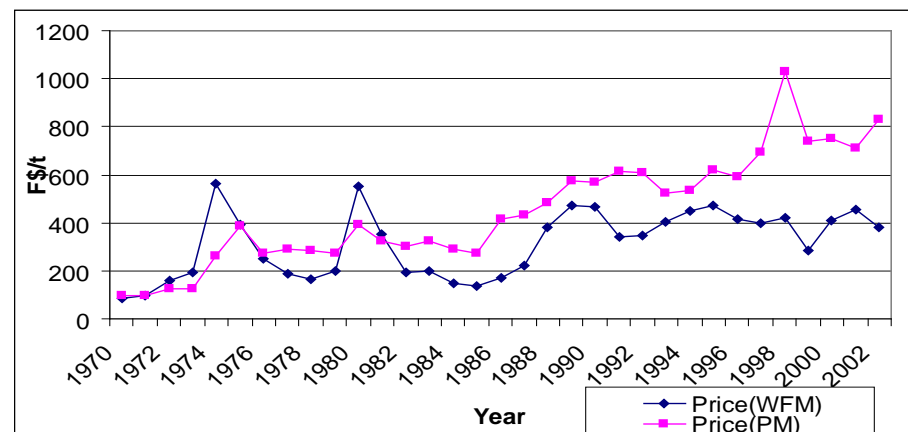

Source: Fiji Bureau of Statistics, Current Economics Statistics Bulletin, 1970-2002.

Note: PM=Preferential, WFM=World Free Market

Responding to the higher price and with support from government and the sugar industry, the farmers increased the area under cane, thus increasing cane supply. The dual effect of increased cane supply and the rising price led to increased export income for Fiji. Thus, over the years, the contribution of sugar to national income 
began to rise. This continued until 1997, when land problems began affecting cane supply, thus affecting export earnings. In 1977, sugar export earnings to Fiji were F\$164.3m. With increase in preferential price and with corresponding increase in sugarcane production and sugar supply, sugar export earnings increased to F\$1.24b in 2000. However, Sugar is now no longer the leading foreign exchange earner. Its contribution to GDP fell to as low as 6.8\% in 2002 (Appendix 2).

\section{Methodology}

This study utilizes secondary data on Fiji's sugar industry for the period 1964 to 2003 to examine three key issues. First, we examine if the world free market price are volatile and if the preferential prices reduced the volatility of prices received by Fiji's sugar industry thus indicating a positive effect of preferential prices on stabilizing farm income. For this a GARCH $(1,1)$ model was estimated for both preferential market and world free market price. Secondly, we test the certainty dimension of the preferential price by examining the role of forecast price as an unbiased and efficient predictor of actual price. The two time series, the actual and forecast price will be regressed together and the coefficients and error term will be tested for unbiassness and efficiency. Finally, we examine how sugar cane supply is affected by output price by estimating an Error Correction Model.

\section{Results and Discussion}

\section{(i) Testing Volatility of Preferential and World Free market Price}

Volatility of prices is an important measure as it has an implication of stability of export earnings and farm income. Volatility can be measured in several ways. In this paper, we use the most commonly used model, the GARCH $(1,1)$ model which is stated as follows:

$\mathrm{Y}_{\mathrm{t}}=\mathrm{x}_{\mathrm{t}}^{\prime} \theta+\varepsilon_{\mathrm{t}}$

Where the above is the conditional mean equation with $x_{t}$ being the vector of exogenous variables. The conditional variance, $\sigma^{2}$, can be stated as follows:

$\sigma_{\mathrm{t}}^{2}=\omega+\alpha \varepsilon_{\mathrm{t}-1}^{2}+\beta \sigma_{\mathrm{t}-1}^{2}$

where $\omega$ is a constant term, $\alpha \varepsilon^{2}{ }_{\mathrm{t}-1}$ is the ARCH term and $\beta \sigma_{\mathrm{t}-1}^{2}$ is the GARCH term.

Often conditional distribution for future prices, given past prices is Non-Gaussian. GARCH models can be built using non-Gaussian conditional distribution. The two GARCH $(1,1)$ models of Preferential Market Price (PMP) and World Free market Price (WFP) are given below. For the PMP model, the mean equation is highly significant with a $\mathrm{p}$ value of 0.000 . The GARCH model is as follows: 


$$
\begin{aligned}
\sigma^{2}= & 248.7+1.46 \varepsilon_{t-1}^{2}-0.025 \sigma_{t-1}^{2} \\
& (0.822)(0.098)(0.901)
\end{aligned}
$$

Note that in this model, both the ARCH and GARCH terms are insignificant. Thus implying no significant volatility of preferential market price.

For the WFP model, the mean equation is highly significant with a $\mathrm{p}$ value of 0.000 . The GARCH model is as follows:

$$
\sigma_{t}^{2}=\begin{array}{ll}
1310.31 & -0.219 \varepsilon_{t-1}^{2}+1.131 \sigma_{t-1}^{2} \\
(0.545) & (0.666)
\end{array}
$$

In this model as well, both the ARCH and GARCH terms are insignificant. This implies that there was no case for use of preferential prices to be used to stabilize world free market price since the world free market price is not volatile at all. In summary, the above analysis demonstrates that given the world free market price was not volatile, the reason of stabilizing farm income by providing price subsidy is not valid. Therefore, the prime motive of price subsidy was to provide aid to the country via the sugar export crop. The government benefited directly by the price formulae ( $70 \%$ accrues to farmer and $30 \%$ to miller) as well as indirectly via farmers expenditure on consumption.

\section{(ii) Testing Efficiency of Forecast Prices}

The time series of forecast and actual price are provided in Appendix 3. The efficiency of sugarcane forecast price (FP) for actual price (AP) can be modeled by the use of rational expectations theory where the relationship can be stated as:

$$
\mathrm{AP}_{\mathrm{t}}=\alpha+\beta \mathrm{FP}_{\mathrm{t}-\mathrm{k}, \mathrm{t}}+\mathrm{w}_{\mathrm{t}}
$$

Where $\alpha$ and $\beta$ are unknown coefficients and $\mathrm{w}_{\mathrm{t}}$ is an error term reflecting the impact of news arriving during the contract period. The are two testable hypothesis associated with the equation given above: they are unbiased ness and predictive efficiency: The forecast price is an unbiased predictor of the spot price when $(\alpha, \beta)=(0,1)$. On the other hand, the future price is said to be efficient predictor if the error term shows no autocorrelation, namely $\mathrm{E}\left(\mathrm{w}_{\mathrm{t}} \mathrm{w}_{\mathrm{t}-\mathrm{j}}\right)=0$ for all $\mathrm{j}$. If this condition is violated, a profitable trading rule based on this serial correlation can be developed.

The estimated model of actual price is presented below:

$$
\mathrm{AP}=\begin{gathered}
3.89 \\
(1.187)
\end{gathered} \quad \begin{aligned}
& 1.17 \mathrm{FP} \\
& (0.00)
\end{aligned}
$$


The model has a good fit with adjusted $\mathrm{R}^{2}$ of $84.3 \%$. The constant term is not significantly different from zero at $5 \%$ level of significance. Therefore, we do not reject the null hypothesis. A Wald test of coefficient of the FP variable equal to 1 provides a p-value of 0.066 . Again the p-value is higher than 0.05 therefore we accept the null hypothesis saying that forecast price is an unbiased predictor of actual price. We then test for efficiency of the model by testing for the serial correlation of the error term. The p-value of the serial correlation LM test is 0.232 , higher than 0.05 . Therefore, we conclude that there is evidence to suggest that future price is an efficient predictor of actual price.

\section{(iii) Examining Supply Response to Preferential Price}

Microeconomic studies of supply response are very few in the economics literature primarily because of lack of farm level data. The limited number of studies that exists either uses the single commodity model of Nerlove (1958) or the aggregate supply response model developed by Griliches (1960). Both of these approaches use the OLS to estimate the dynamic specification of their supply response thus assuming that the underlying data processes are stationary. However, most economic variables tend to be non-stationary thus OLS regression may be spurious (Granger and Newbold, 1974). Therefore, cointegration analysis can be used with non stationary data to avoid spurious regressions (Banerjee, et. al,. 1993). Within this framework, the error correction models (ECM) can provide both the long run and short run elasticities. There are a number of studies that have used ECMs (see Hallam and Zanoli, 1993; Abdulai and Rieder, 1995; Townsend, 1996 and Tambi, 1999). Another problem with some of these studies is that they tend to provide supply elasticities for changes in physical inputs ignoring the role of prices on the production and input allocation decisions of farmers. Furthermore, these studies tend to ignore key non price factors that condition farmers response such as rainfall. In fact, the dual approach where the dual profit function can be used to derive supply function by applying Hotelling's Lemma ${ }^{2}$ provides an output supply function which is a function of output and input prices and other exogenous factors. In this study, we specify the dual supply response function of sugarcane as follows:

$\mathrm{SCS}_{\mathrm{t}}=f\left(\mathrm{SCP}_{\mathrm{t}}, \mathrm{IP}_{\mathrm{t}}, \mathrm{Z}_{\mathrm{t}}\right)$

Where $\mathrm{SCS}_{\mathrm{t}} \quad$ = Sugarcane supply;

$\mathrm{SCP}_{\mathrm{t}} \quad=$ sugarcane price;

$\mathrm{IP}_{\mathrm{t}} \quad=$ input prices

$\mathrm{Z}_{\mathrm{t}} \quad=$ other exogenous factors such as area under crop and rainfall.

$\mathrm{y}_{\mathrm{m}}(\mathrm{p}, \mathrm{w} ; \mathrm{z})=\partial \pi(\mathrm{p}, \mathrm{w} ; \mathrm{z}) / \partial \mathrm{p}_{\mathrm{m}}$ where $\mathrm{y}_{\mathrm{m}}(\mathrm{p}, \mathrm{w} ; \mathrm{z})$ is the dual supply function, $\pi(\mathrm{p}, \mathrm{w} ; \mathrm{z})$ is the dual profit function $\mathrm{p}_{\mathrm{m}}$ is the output price, $\mathrm{w}$ is vector of input price and $\mathrm{z}$ is a vector of exogenous factors. 
The input prices are not included in the model because of lack of time series data on inputs. The variable for which price is available, there is very little variation over the study period. This is particularly the case of fertilizer which is provided by the industry to the farmers.

Before estimating the above equation, we need to ascertain the presence of unit roots and cointegration. Unit Root testing for stationarity involves the identification of whether a time series needs to be differenced to stationarity. A time series with a unit root has a long term component that is purely non-predictable. There exist a number of techniques to undertake unit roots test. Amongst these, the most widely used are the Dickey and Fuller (1979) test.

For example, for the Sugarcane supply series, the following model will be examined:

$\Delta \operatorname{SCS}_{t}=\mu+\gamma \operatorname{SCS}_{t-1}+\psi \Delta \operatorname{SCS}_{t-1}+\ldots+\psi q \operatorname{SCSR}_{t-q}+\varepsilon_{t}$

T-test ( $\tau$ statistic)

H0: $\gamma=0(\alpha=1$, RW with drift $)$

H1: $\gamma<0(\alpha<1$, trend stationary)

Augmented Dickey-Fuller Test Statistic does not follow a normal distribution even when the sample size is very large (or asymptotically). They asymptotically follow the distribution tabulated by Dickey and Fuller. The Dickey-Fuller distribution is not symmetric and skewed to the right. The decision rule involves reject $\mathrm{H} 0$ if $\tau<\mathrm{DF}$ critical value. The unit root test for all the series revealed non rejection of $\mathrm{HO}$ for all three series thus suggesting that they have unit root.

The testing for cointegration utilizes the two stage procedure of Engle-Granger (1987). Cointegration test can also be done using the more advanced Vector Autoregressive (VAR) model. However, the VAR approach has large data requirement and thus it is not appropriate for this case where we have only 42 time period.

Therefore, the cointegrating equation is stated as follows:

$S C S_{t}=\beta_{0}+\beta_{1} S C P_{t}+\beta_{2} \operatorname{Area}_{t}+\varepsilon_{t}$

The test involves running the above cointegrating regression and then the residuals $\varepsilon_{t}$ 's are subjected to the ADF test procedure:

- $\mathrm{H}_{0}: \varepsilon_{t} \sim \mathrm{I}(1)$ (No cointegration)

- $\mathrm{H}_{1}: \varepsilon_{t} \sim \mathrm{I}(0)$ (cointegration) 
The results from the tests indicate that the variables are cointegrated. Following this result, two long run equations are estimated. The first one is the output supply equation and the second one is the acreage response equation.

\section{Long Run Model}

The estimates of the long-run model are given in Table $1 \& 2$ below. Results from the estimates of the long-run model reveal that the only variable that significantly affects output supply is area under cultivation in the current period.

Table 1: Long-run Sugarcane Crop Supply Function, 1961-2003.

\begin{tabular}{lcc}
\hline Variable & Coefficient & P value \\
\hline $\mathrm{C}$ & 3.311 & 0.000 \\
$\mathrm{SCA}$ & 1.229 & 0.000 \\
$\mathrm{SCP}$ & -0.089 & 0.062 \\
Adjusted $\mathrm{R}^{2}$ & 0.778 & \\
$\mathrm{~N}=42$ & & \\
\hline
\end{tabular}

Note: All variables are in natural logs.

The area under crop is in turn affected by its own lagged variable and two period lagged effect of price. This makes sense because acreage changes in sugarcane crop takes time because of the ratoon nature of the crop. Therefore, this year's acreage is strongly influenced by last year's acreage. Furthermore, the acreage is also affected by price two periods lagged. The explanation for this that a high price this year will see new crop planted late this season which cannot be harvested next year. Therefore, it will be harvested in the following year which is the reason for the significance of the price variable lagged two years.

Table 2: Long-Run Sugarcane Acreage Response Function, 1961-2003.

\begin{tabular}{lcc}
\hline Variable & Coefficient & P value \\
\hline $\mathrm{C}$ & 1.222 & 0.0001 \\
$\mathrm{SCA}_{-1}$ & 0.647 & 0.0000 \\
$\mathrm{SCP}_{-2}$ & 0.070 & 0.0056 \\
$\mathrm{~N}$ & 42 & \\
Adjusted $\mathrm{R}^{2}$ & 0.908 & \\
\hline
\end{tabular}

\section{The Short Run Error Correction Model}

To measure the short run dynamics, the short-run model with the lagged value of residuals from the corresponding long run equations is estimated in the error correction framework. The ADF test statistic for cointegration of the two equations were estimated. The output equation had -7.92 while the area equation had the test statistic equal to -6.76 thus rejecting the null hypothesis of no cointegration. The 
two models are presented in Tables 3 and 4 below. For the crop supply model, both acreage and lagged price have a significant effect on crop output supply. The area under crop is expected to positively affect crop output. Similarly, the larger the price difference in the lagged period has a direct effect on out put supply. This result was not evident over the longer run period as demonstrated by the long run equation. Another important result from this model is that error correction term in this model displays the appropriate (negative) sign and is significant thus consistent with the validity that the series is non-explosive and that the long run equilibrium is attainable.

Table 3: Short-run Sugarcane Crop Supply Function, 1961-2003.

\begin{tabular}{lcc}
\hline Variable & Coefficient & P value \\
\hline $\mathrm{C}$ & -0.030 & 0.0877 \\
$\varepsilon_{-1}$ & -1.354 & 0.0000 \\
$\mathrm{D}(\mathrm{SCA})$ & 2.291 & 0.0000 \\
$\mathrm{D}\left(\mathrm{SCS}_{-1}\right)$ & 0.091 & 0.4423 \\
$\mathrm{D}\left(\mathrm{SCP}_{-1}\right)$ & 0.149 & 0.0327 \\
Adjusted $^{2}$ & 0.852 & \\
$\mathrm{~N}=42$ & & \\
\hline
\end{tabular}

Note: $\mathrm{D}$ is the difference operator.

The acreage response function also has a good fit of $85 \%$. There are three variables that significantly affect acreage response and these are output level, its lagged difference and difference of acreage two period lagged. Another important result from this model, as was the case of the crop supply response model is that the error correction term in this model displays the appropriate (negative) sign and is significant thus consistent with the validity that the series is non-explosive and that the long run equilibrium is attainable.

Table 4: Short-run Sugarcane Acreage Response Function, 1961-2003.

\begin{tabular}{lcc}
\hline Variable & Coefficient & P value \\
\hline $\mathrm{C}$ & -0.001 & 0.8660 \\
$\varepsilon_{-1}$ & -0.364 & 0.0055 \\
$\mathrm{D}(\mathrm{SCS})$ & 0.244 & 0.0000 \\
$\mathrm{D}\left(\mathrm{SCS}_{-1}\right)$ & 0.209 & 0.0000 \\
$\mathrm{D}\left(\mathrm{SCA}_{-2}\right)$ & 0.345 & 0.0001 \\
$\mathrm{D}\left(\mathrm{SCP}_{-2}\right)$ & 0.061 & 0.0149 \\
Adjusted $\mathrm{R}^{2}$ & 0.761 & \\
$\mathrm{~N}=42$ & & \\
\hline
\end{tabular}




\section{Summary and Conclusion}

This study examined the effect of preferential price on Fiji's sugar industry. While it has provided a significant additional source of foreign exchange for Fiji and a much higher farm income for the farmers, it did not have a role to play in stabilizing farm income since the world free market price is not very volatile itself. However, certainty aspect of the preferential price arising out of the various agreements assured that at the farm level, the miller's forecast price for sugarcane has always been an unbiased and efficient predictor of actual price. This finding negates any proposition that the miller used to make liberal forecasts of sugarcane price to boost supply.

These studies have also examined how sugarcane farmers respond to output price. In the long run, output price affects output supply via acreage change. In the short run, it has a more direct affect. However, the supply response to price change is low. In the long run, price elasticity to output supply is only via acreage response and is 0.070 , highly inelastic. In the short run, it is much lower, 0.015, and still inelastic. This has some important policy implication. Fiji's land tenure system where most of the land (90\%) are communally owned are holding back acreage change and therefore cane and other agricultural output supply. Unless Fiji's land tenure system is revisited to make it more flexible in terms of release of land for agricultural production, supply response will always be a problem. Other areas of raising farm and national income would be raising productivity and efficiency and reducing unit cost of production.

While these conclusions are reached, it must be noted that the supply response function used in this paper does not have any proxy for inputs other then land. This makes the model weak in terms of policy implications. It is hoped that in future, once time series input data is available, the model be re-specified and re-estimated for more accurate policy making.

\section{References}

Abbot, D and S. Pollard (2004) Hardship and Poverty in the Pacific, Asian Development Bank, Manila, pp. 151.

Abdulai, A and P. Rieder (1995) 'The Impact of Agricultural Price Policy on Cocoa Supply in Ghana: an Error Correction Estimation”, Journal of African Economies, 4(3):315-335.

Abrar, S., O. Morrissey and T. Rayner (2004) “Aggregate Agricultural Supply Response in Ethiopia: A Farm-Level Analysis”, Journal of International Development, 16(1):605-620.

Banerjee, A., J. Dolado., J. Glabraith and D. Hendry (1993) Co-intergration, Error Correction and the Econometric Analysis of Non-Stationary Data, Oxford: Oxford University Press. 
Dicky, D and W. Fuller (1979) "Distribution of the Estimators for Autoregressive Time Series with a Unit Root”, Journal of the American Statistical Association, 74 (2): 427-431.

Engle, R. F. and C. W. J. Granger (1987) “Cointegration and Error Correction: Representation, Estimation and Testing”, Econometrica, 55(2): 251-276.

FSC (1987) ‘A milestone in Sugar Production’. 1986 FSC Annual Report.

Granger, C and P. Newbold (1974) “Spurious Regressions in Economics”, Journal of Econometrics, 2(1):227-238.

Griliches, Z (1960) “Estimates of the Aggregate US Farm Supply Functions”, Journal of Farm Economics, 42(2):282-293.

Hallam, D. and R. Zanoli (1993) "Error Correction Models and Agricultural Supply Response”, European Review of Agricultural Economics, 2(2):111-120.

Hughes, H (2003) “Aid Has Failed the Pacific", The Centre for Independent Studies, Issue Analysis, No. 33, pp. 1-32.

Nerlove, M (1958) “Distributed Lags and Estimation of Long Run Supply and Demand Elasticities: Theoretical Considerations”, Journal of Farm Economics, 40(2):301-311.

Reddy, M and R. Duncan (2006) "Institutions and Growth in the Pacific", Paper presented at the 2006 Sixth Annual Global Development Conference, Dakar Senegal, January, 26-30, 2006.

Tambi, N. E (1999) “Co-integration and Error-Correction Modeling of Agricultural Export Supply in Cameroon”, Agricultural Economics, 20(1):57-67.

Townsend, R (1996) "Price Liberalisation, Technology and Food Self Sufficiency: An Analysis of Summer Grains in South Africa”, Mimeo. 
Appendices

Appendix 1: Sugar and Cane Production in the Colonial Era, 1961-1970

\begin{tabular}{|c|c|c|c|c|}
\hline Year & No. of Contracts & $\begin{array}{l}\text { Area Harvested } \\
\text { ('000 ha) }\end{array}$ & $\begin{array}{c}\text { Sugar Cane } \\
\text { Production }(000 \mathrm{t})\end{array}$ & $\begin{array}{c}\text { Sugar Production } \\
(000 \mathrm{t})\end{array}$ \\
\hline 1961 & 13948 & 26 & 1148 & 144 \\
\hline 1962 & 13921 & 31 & 1824 & 248 \\
\hline 1963 & 13924 & 36 & 2337 & 299 \\
\hline 1964 & 14100 & 42 & 2319 & 308 \\
\hline 1965 & 14798 & 43 & 2171 & 311 \\
\hline 1966 & 15579 & 43 & 2227 & 309 \\
\hline 1967 & 15609 & 45 & 2197 & 297 \\
\hline 1968 & 15596 & 46 & 2871 & 399 \\
\hline 1969 & 15596 & 47 & 2376 & 305 \\
\hline 1970 & 15542 & 46 & 2886 & 361 \\
\hline 1971 & 15548 & 47 & 2545 & 323 \\
\hline 1972 & 15612 & 44 & 2238 & 303 \\
\hline 1973 & 16533 & 46 & 2496 & 301 \\
\hline 1974 & 16546 & 45 & 2151 & 272 \\
\hline 1975 & 17264 & 45 & 2160 & 264 \\
\hline 1976 & 17667 & 47 & 2283 & 286 \\
\hline 1977 & 18395 & 52 & 2674 & 362 \\
\hline 1978 & 18456 & 54 & 2853 & 347 \\
\hline 1979 & 19152 & 62 & 4063 & 473 \\
\hline 1980 & 19700 & 66 & 3360 & 396 \\
\hline 1981 & 21000 & 66 & 3931 & 470 \\
\hline 1982 & 21574 & 69 & 4075 & 487 \\
\hline 1983 & 21880 & 59 & 2203 & 276 \\
\hline 1984 & 22130 & 69 & 4290 & 480 \\
\hline 1985 & 22159 & 70 & 3042 & 341 \\
\hline 1986 & 22182 & 69 & 4109 & 502 \\
\hline 1987 & 22255 & 66 & 2960 & 401 \\
\hline 1988 & 22127 & 64 & 3185 & 363 \\
\hline 1989 & 21771 & 71 & 4099 & 461 \\
\hline 1990 & 21334 & 70 & 4016 & 408 \\
\hline 1991 & 24479 & 73 & 3380 & 389 \\
\hline 1992 & 23334 & 73 & 3533 & 426 \\
\hline 1993 & 23454 & 74 & 3704 & 442 \\
\hline 1994 & 23264 & 74 & 4064 & 517 \\
\hline 1995 & 22449 & 74 & 4110 & 454 \\
\hline 1996 & 22304 & 74 & 4380 & 454 \\
\hline 1997 & 22100 & 73 & 3280 & 347 \\
\hline 1998 & 22146 & 57 & 2098 & 266 \\
\hline 1999 & 22178 & 65 & 3958 & 377 \\
\hline 2000 & 22179 & 63 & 3786 & 341 \\
\hline 2001 & 21882 & 66 & 2805 & 293 \\
\hline 2002 & 21246 & 65 & 3423 & 330 \\
\hline 2003 & 21253 & 61 & 2610 & 294 \\
\hline
\end{tabular}

Source: Current Economic Statistics Bulletin, Fiji Bureau of Statistics, (January 1990 and March 2004). 
Appendix 2: Sugarcane and Sugar in GDP and Exports, 1977-2002

\begin{tabular}{ccccc}
\hline Year & $\begin{array}{c}\text { Sugarcane } \\
\text { as \%age of GDP }\end{array}$ & $\begin{array}{c}\text { Sugar as \%age of } \\
\text { GDP }\end{array}$ & $\begin{array}{c}\text { Total Sugar as } \\
\text { \% age of GDP }\end{array}$ & $\begin{array}{c}\text { Sugar Exports as } \\
\text { \%age Total Exports }\end{array}$ \\
\hline 1977 & 10.2 & 3.9 & 14.2 & 57.0 \\
1978 & 9.7 & 3.7 & 13.4 & 50.0 \\
1979 & 11.7 & 4.5 & 16.3 & 54.4 \\
1980 & 10.1 & 3.9 & 14.1 & 59.0 \\
1981 & 11.4 & 4.4 & 15.8 & 48.9 \\
1982 & 11.7 & 4.5 & 16.2 & 46.7 \\
1983 & 7.0 & 2.7 & 9.7 & 45.7 \\
1984 & 11.1 & 4.3 & 15.4 & 39.2 \\
1985 & 8.3 & 3.2 & 11.5 & 41.2 \\
1986 & 11.3 & 4.4 & 15.6 & 42.8 \\
1987 & 9.6 & 3.7 & 13.3 & 45.8 \\
1988 & 8.6 & 3.3 & 12.0 & 37.3 \\
1989 & 9.9 & 4.0 & 14.0 & 34.7 \\
1990 & 8.5 & 3.5 & 12.0 & 30.6 \\
1991 & 8.3 & 3.4 & 11.7 & 33.1 \\
1992 & 8.6 & 3.5 & 12.1 & 33.2 \\
1993 & 8.7 & 3.5 & 12.2 & 33.1 \\
1994 & 9.6 & 3.9 & 13.5 & 30.3 \\
1995 & 8.3 & 3.4 & 11.7 & 31.5 \\
1996 & 8.0 & 3.3 & 11.3 & 28.7 \\
1997 & 6.2 & 2.5 & 8.7 & 23.8 \\
1998 & 4.5 & 1.8 & 6.3 & 14.4 \\
1999 & 5.8 & 2.3 & 8.2 & 7.8 \\
2000 & 5.5 & 2.3 & 7.0 & \\
2001 & 5.0 & 2.0 & 6.8 & \\
2002 & 4.9 & 2.0 & & 2.1 \\
\hline
\end{tabular}

Source: Current Economic Statistics (1978-2004). 
Appendix 3: Actual and Forecast Price, 1972-2003.

\begin{tabular}{|c|c|c|}
\hline Year & $\begin{array}{c}\mathrm{FP} \\
\text { (F\$/ton) }\end{array}$ & $\begin{array}{c}\mathrm{AP} \\
\text { (F\$/ton) }\end{array}$ \\
\hline 1972 & 9.58 & 10.23 \\
\hline 1973 & 9.58 & 9.91 \\
\hline 1974 & 12.50 & 20.90 \\
\hline 1975 & 25.00 & 32.12 \\
\hline 1976 & 20.00 & 26.33 \\
\hline 1977 & 20.00 & 27.03 \\
\hline 1978 & 20.00 & 24.99 \\
\hline 1979 & 20.00 & 23.64 \\
\hline 1980 & 24.00 & 35.19 \\
\hline 1981 & 20.00 & 26.24 \\
\hline 1982 & 20.00 & 29.65 \\
\hline 1983 & 21.00 & 29.65 \\
\hline 1984 & 19.00 & 21.87 \\
\hline 1985 & 20.00 & 23.52 \\
\hline 1986 & 25.65 & 36.55 \\
\hline 1987 & 23.50 & 52.39 \\
\hline 1988 & 33.50 & 44.16 \\
\hline 1989 & 38.50 & 46.47 \\
\hline 1990 & 43.70 & 41.30 \\
\hline 1991 & 36.85 & 50.89 \\
\hline 1992 & 39.21 & 54.98 \\
\hline 1993 & 39.37 & 49.16 \\
\hline 1994 & 37.08 & 50.97 \\
\hline 1995 & 39.18 & 53.78 \\
\hline 1996 & 39.21 & 44.81 \\
\hline 1997 & 38.62 & 50.07 \\
\hline 1998 & 48.61 & 81.78 \\
\hline 1999 & 41.70 & 50.76 \\
\hline 2000 & 36.72 & 44.01 \\
\hline 2001 & 43.03 & 60.80 \\
\hline 2002 & 43.99 & 53.79 \\
\hline 2003 & 43.50 & 60.12 \\
\hline
\end{tabular}

Source: Fiji Sugar Co-operation, 2006. 